\title{
A cell-based, high-throughput homogeneous time- resolved fluorescence assay for the screening of potential k-opioid receptor agonists
}

\author{
Yue WANG ${ }^{1, \#}$, Ming YAN ${ }^{2, \#}$, Guang-yao ZHENG ${ }^{3, \#}$, Ling HE ${ }^{1, *}$, Huan YANG ${ }^{1}$ \\ ${ }^{1}$ Department of Pharmacology, China Pharmaceutical University, Nanjing 210009, China; ${ }^{2}$ National Drug Screening Laboratory, China \\ Pharmaceutical University, Nanjing 210009, China; ${ }^{3}$ Institute of Chemistry and Industry of Forest Products, National Engineering \\ Laboratory for Biomass Chemical Utilization; Key and Open Laboratory of Forest Chemical Engineering, Key Laboratory of Biomass \\ Energy and Material, Nanjing 210042, China
}

\begin{abstract}
Aim: The aim of this study was to identify k-opioid receptor (KOR) agonists from a library of 80000 small-molecule compounds and provide the experimental basis for the development of new analgesic candidates.

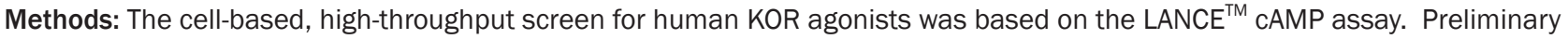
structure-activity relationship (SAR) analysis was applied according to the compounds' structures. An acetic acid twisting experiment was used to verify the pharmacodynamics.

Results: In total, 31 compounds were identified as KOR agonists after preliminary and secondary screening. Of these compounds, five

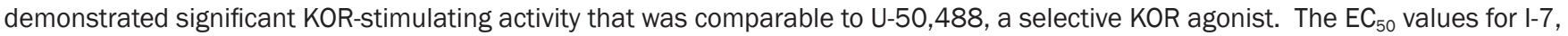
I-8, I-10, II-5, and II-8 were 13.34 $\pm 1.65,14.01 \pm 1.84,9.57 \pm 0.19,14.94 \pm 0.64$, and 8.74 $\pm 0.72 \mathrm{nmol} / \mathrm{L}$, respectively. Based on SAR studies, the stimulating activity of compounds with 5-phenyl-7-(trifluoromethyl)-4,5,6,7-tetrahydropyrazolo [1, 5-a] pyrimidine (group I) and 3,4-dimethoxy- $N$-(2-oxoethyl)- $N$-p-tolylbenzenesulfonamide (group II) parent structures were higher than the compound with a 5-hydroxy-2-methylbenzofuran-3-carboxylic acid (group III) parent structure. Pharmacodynamic experiments indicated that 20-40 $\mu \mathrm{g} / \mathrm{kg}$ ip of compounds I-10 and II-8 significantly decreased the number of writhes induced by acetic acid; this finding is consistent with the SAR studies. Furthermore, the analgesic effects of compounds I-10 and II-8 were significantly antagonized in the presence of the selective KOR antagonist nor-BNI.

Conclusion: These findings collectively indicate that compounds I-10 and II-8 exhibit significant analgesic activities, providing evidence, at least in part, for their clinical application as new analgesic drugs.
\end{abstract}

Keywords: K-opioid receptor agonists; LANCE ${ }^{\mathrm{TM}}$ CAMP assay; high-throughput screening; structure-activity relationship; writhing test

Acta Pharmacologica Sinica (2014) 35: 957-966; doi: 10.1038/aps.2014.21; published online 16 Jun 2014

\section{Introduction}

$\mathrm{G}$ protein-coupled receptors (GPCRs) represent the largest family of membrane proteins in the human genome and the richest source of targets for the pharmaceutical industry ${ }^{[1]}$. GPCRs are divided into the following five families based on their physico-chemical properties: rhodopsin-like, secretinlike, metabotropic glutamate, fungal pheromone and cAMP receptors $^{[2]}$. The peptidergic opioid receptors (ORs) belong to the rhodopsin-like family. ORs are classified into the

\footnotetext{
\#These authors contributed equally to this work.

* To whom correspondence should be addressed.

E-mail heling92@hotmail.com

Received 2013-09-27 Accepted 2014-01-22
}

following three subtypes based on detailed investigations of the pharmacological effects using selective ligands: the muopioid receptor (MOR), the delta-opioid receptor (DOR) and the kappa-opioid receptor $(\mathrm{KOR})^{[3]}$. Among the three opioid receptor genes, the KOR gene is the first to exhibit its gene activity (mRNA expression) during development. KOR expression then increases in the nervous system throughout the later stages of development when active neuritogenesis occurs $^{[4]}$.

Various GPCRs, including KOR, synthesize adenylyl cyclase (AC)-catalyzed cAMP (from ATP) within their pathways. KOR is coupled with the a inhibitory subunit (Gai) of the G-protein that downregulates AC activity upon activation. Consequently, cAMP production inhibits protein 
kinase A (PKA $)^{[5]}$. Thus, it is possible to assess the activity of KOR agonists by quantitatively detecting intracellular cAMP concentrations. In this study, we used the $\mathrm{LANCE}^{\mathrm{TM}} \mathrm{CAMP}$ assay, a homogeneous time-resolved fluorescence resonance energy transfer (TR-FRET)-based assay, to screen 80000 smallmolecule compounds for potential KOR agonists. These assay reactions are stable for at least $20 \mathrm{~h}$ at room temperature with minimal loss in sensitivity. The sensitivity and robustness of the LANCE ${ }^{\mathrm{TM}}$ cAMP assay makes it ideal for HTS screening campaigns.

KOR is widely distributed in the central and peripheral nervous system and predominantly localized in the cerebral cortex, nucleus accumbens, claustrum and hypothalamus. KOR stimulation produces various physiological functions, such as analgesia, antipruritic activity, diuresis, stress, depression, drug abuse, anxiety and psychotic behaviors ${ }^{[6-8]}$. Therefore, $\mathrm{KOR}$ is rapidly emerging as an important target for the treatment of a variety of human disorders. At present, KOR agonists have attracted considerable attention because of their abilities to exert potent analgesic effects without high abuse liability ${ }^{[9,10]}$ and to minimize serious MOR-mediated side effects, including respiratory depression and dependence liability $^{[11-13]}$. Delta opioid receptor (DOR) agonists can produce analgesia, but these compounds also have serious side effects, most notably convulsions ${ }^{[14]}$, that limit their therapeutic development. By contrast, new potential therapeutic applications have recently been recognized for KOR agonists, underscoring the clinical value of the development of agents for this receptor. Opioid analgesics produce antinociception through their action on the peripheral and central opioid receptors in acute and chronic pain states. Studies in animal models describe a number of peripheral and central pathophysiological processes after nerve injury that serve as underlying neuropathic pain mechanisms ${ }^{[15]}$.

Here, we investigated the antinociceptive effects and pharmacological activity of the KOR agonists using the acidinduced writhing test. This well-established nociceptive method employs a chemical stimulus and is more sensitive than other tests that use thermal, mechanical or electrical stimuli. Compounds I-10 and II-8 displayed significant analgesic effects. These experimental data support the development of new analgesic candidates.

\section{Materials and methods}

\section{Chemicals and reagents}

Ham's F12 medium and fetal bovine serum (FBS) were purchased from Invitrogen (Carlsbad, CA, USA). Ethylenediamine tetraacetic acid (EDTA) and dimethyl sulfoxide (DMSO) were obtained from Sigma (St Louis, MO, USA). Forskolin, 3-isobutyl-1-methylxanthine (IBMX) and bovine serum albumin (BSA) were obtained from Calbiochem (San Diego, CA). U-50488 hydrochloride [trans- $( \pm)-3,4$-dichloro- $N$ methyl-N-[2-(1-pyrrolidinyl) cyclohexyl] benzeneacetamide hydrochloride] and nor-binaltorphimine dihydrochloride $\left[17,17^{\prime}\right.$-(dicyclopropylmethyl)-6,6', 7,7' -6,6'-imino-7,7' -binorphinan-3, $4^{\prime}, 14,14^{\prime}$-tetrol dihydrochloride] were purchased from
Tocris (Ellisville, MO, USA). Chinese hamster ovary cells were stably transfected with the human KOR $\left(\mathrm{CHO}-\mathrm{OP}_{2}\right.$ cell line). LANCE $^{\mathrm{TM}}$ CAMP 384 kit, 384-well white optiplates and TopSeal-A 384 were obtained from PerkinElmer (Waltham, MA, USA). The 96-well clear round bottom microplates were purchased from Corning (Corning, NY, USA). The tested compounds were obtained from ChemDiv, Inc (San Diego, CA, USA). Hank's balanced salt solution (HBSS) and phosphate-buffered saline (PBS) were made from our own laboratory stocks. Stimulation buffer (SB) was prepared from HBSS containing $10 \mathrm{mmol} / \mathrm{L}$ HEPES, 0.2\% BSA and $1 \mathrm{mmol} / \mathrm{L}$ IBMX (pH 7.4). Forskolin (50 mmol/L), U-50488 (25 mmol/L), nor-binaltorphimine dihydrochloride $(25 \mathrm{mmol} / \mathrm{L})$ and compounds $(10 \mathrm{mg} / \mathrm{mL})$ stock solutions were prepared in DMSO. All stocks were stored at $-20^{\circ} \mathrm{C}$ and diluted to certain concentration with HBSS prior to use. All stocks used on animals were dissolved in saline. Acetic acid and normal saline (NS) were from our own laboratory stocks. All other chemicals were of analytic grade and commercially available.

\section{Experimental animals}

Eighty adult male and female Kunming mice (20-30 g) from the medical animal center of Yangzhou University were used in this study. The animals were housed in controlled environmental conditions $\left(24 \pm 2{ }^{\circ} \mathrm{C}\right.$ temperature, $60 \%-70 \%$ relative humidity, $12 \mathrm{~h}$ light/dark cycle) and were provided a standard pellet diet and water ad libitum. All procedures were conducted in accordance with the Guidelines on the Care and Use of Laboratory Animals (Chinese Council on Animal Research and the Guidelines of Animal Care). The study was approved by the Ethical Committee of China Pharmaceutical University. Each mouse was used for a single treatment, and each group consisted of ten animals.

\section{Cell culture}

$\mathrm{CHO}_{-} \mathrm{OP}_{2}$ cell line was purchased from PerkinElmer company, which expressed kappa-opioid receptor specifically. They were maintained at approximately $85 \%$ confluence in Ham's F12 medium supplemented with 10\% FBS, $100 \mathrm{IU} / \mathrm{mL}$ penicillin, $100 \mu \mathrm{g} / \mathrm{mL}$ streptomycin, $5 \mu \mathrm{g} / \mathrm{mL}$ blasticidin at $37^{\circ} \mathrm{C}$ in a $5 \% \mathrm{CO}_{2}$ humidified environment. The cells were harvested using PBS containing $0.5 \mathrm{mmol} / \mathrm{L}$ EDTA. Then, the cells were washed with HBSS before being suspended in SB for assay use.

\section{Establishment of screening model Optimization of the LANCE ${ }^{T M}$ CAMP assay}

To establish a stable and reliable cell-based, high-throughput screening system to identify potential KOR agonists, several parameters were optimized, including cell density, stimulation time and forskolin concentration in the $\mathrm{LANCE}^{\mathrm{TM}} \mathrm{CAMP}$ assay. In brief, $\mathrm{CHO}-\mathrm{OP}_{2}$ cells were processed as described above. The Countness ${ }^{\mathrm{TM}}$ automated cell counter (Invitrogen, Carlsbad, CA) was used to count cells, and the cell density was adjusted to 300,600 , and 1200 cells $/ \mu \mathrm{L}$ with SB containing 1\% Alexa Fluor® 647 anti-cAMP antibody (supplied with the 
LANCE $^{\mathrm{TM}}$ cAMP assay kit). Next, $5 \mu \mathrm{L}$ aliquots of the cell suspensions of various concentrations were added to wells in the 384-well white optiplate with a Multidrop (Thermo Electron Corp, Waltham, MA) followed by the addition of $5 \mu \mathrm{L}$ of forskolin from a dilution series (final concentration ranged from 1.69 to $3703.7 \mathrm{nmol} / \mathrm{L}$ to generate a forskolin dose-response curve). To optimize the experiment, various cell suspension densities and the forskolin dilution series were incubated for 0 to $60 \mathrm{~min}$ at room temperature (RT) with a 15-min interval, and 4 time points were generated. The forskolin stock solution dilution and the dilution series transfer were performed by the Janus automated workstation (PerkinElmer, Waltham, MA, USA). cAMP standard curves were prepared in parallel using various cell densities with the same stimulation time. Then, 10 $\mu \mathrm{L}$ of the detection mix was added using the Janus automated workstation, and the plate was incubated for $1 \mathrm{~h}$. The final assay volume was $20 \mu \mathrm{L}$. To control for assay reagent evaporation during processing, a plate cover and TopSeal-A 384 was used during incubations. The signals (ratio of fluorescent values at $665 \mathrm{~nm}$ to $615 \mathrm{~nm}$ ) were analyzed using the Envision (PerkinElmer, Waltham, MA, USA) multilabel reader according to the manufacturer's instruction.

To determine the optimal cell density, forskolin doseresponse curves under the same stimulation time were compared with corresponding cAMP standard curves. In addition, the signal to background ratio ( $S / B$, equals the ratio of the maximal signal to the minimal signal in a curve) of all curves and the optimal forskolin concentration were calculated. The optimization assay was performed via three experiments conducted in triplicate.

\section{Verification of positive drug assay}

CHO-OP 2 cells were collected as previously mentioned and modulated to the optimal cell density. For these experiments, $5 \mu \mathrm{L}$ aliquots of the cell suspension were seeded into a 384well white optiplate using the Multidrop, and the cells were stimulated with $2.5 \mu \mathrm{L}$ of the U-50488 dilution series (final concentration ranged from 0.005 to $10 \mu \mathrm{mol} / \mathrm{L}$ to generate agonist dose-response curves) for $15 \mathrm{~min}$. U-50488 stock solution dilutions and transfers were performed by the Janus automated workstation. Then, $2.5 \mu \mathrm{L}$ pf forskolin in the optimal concentration was dispensed into each well using the Flexdrop (PerkinElmer, Waltham, MA, USA). The plate was incubated for the optimized stimulation time. A cAMP standard curve was generated in parallel. Then, $10 \mu \mathrm{L}$ of the detection mix was added to each well. After $1 \mathrm{~h}$, the signals were analyzed using the Envision multilabel reader. All incubations were conducted at RT. To assess assay sensitivity and robustness, the minimal compound stimulating activity control ( $0 \%$ control, cells exposed to HBSS containing an optimized concentration of forskolin) and the maximal compound stimulating activity control (100\% control, cells exposed to HBSS only) were prepared to calculate the $Z^{\prime}$ factor value, a measure of assay quality for high-throughput screening (HTS) applications that is calculated according to Zhang et al, 1999 ${ }^{[16]}$. Compared with the cAMP standard curve, intracellular cAMP concentrations were quantitatively determined, and the half maximal effective concentration $\left(\mathrm{EC}_{50}\right)$ of U-50488 was calculated.

\section{High-throughput screening of potential KOR agonists Preliminary screening}

The compound library used for the screening was composed of 80000 compounds. The final concentration of compounds was $10 \mu \mathrm{g} / \mathrm{mL}$ in 1\%o DMSO (the DMSO concentration did not affect the performance of the assay). Briefly, $0.5 \mu \mathrm{L}$ of the compound stock solution was added to each well of a 96-well clear round bottom microplate. Then, the Janus automated workstation was used to dilute the solutions 250 times and transfer $2.5 \mu \mathrm{L}$ of the dilution to the 384-well white optiplates. Columns № 1 and № 24 were reserved to define the $0 \%$ and $100 \%$ controls. Cell dispensing was performed as previously described. The following steps were conducted sequentially as previously mentioned: 15 min preincubation, 45 min stimulation with $2.5 \mu \mathrm{L}$ of forskolin stimulation, an additional $1 \mathrm{~h}$ incubation following the addition of $10 \mu \mathrm{L}$ of the detection mix, and signal detection. The stimulating activity of compounds at KOR was calculated as Eq (1): Stimulation $\%=\left(\right.$ Signal $_{\text {compound }}-$ Signal $\left._{\mathrm{AV} 0 \% \text { control }}\right) \times 100 \% /\left(\right.$ Signal $_{\mathrm{AV} 100 \% \text { control }^{-}}$ Signal $_{\mathrm{AV} 0 \% \text { control }}$ ), where AV represents the average value of the signals. The raw data were saved in the Envision Database and further processed using ActivityBase Suite (IDBS, Guildford, UK). ActivityBase provides relatively complete information about the compounds, including the stimulation percentages. Compounds causing greater than $80 \%$ stimulating activity were selected for secondary screening to calculate their $\mathrm{EC}_{50}$ values. Moreover, the $\mathrm{Z}^{\prime}$ factor value of each plate was calculated to estimate the efficacy of this assay in adaptation to HTS.

\section{Secondary screening}

Compounds that exhibited stimulation percentages greater than $80 \%$ in the preliminary screening were chosen for further experiments to assess their ability to stimulate KOR. In total, 4 -fold serial dilutions from the compound stock solutions to prepare eight dilution series (final concentration ranged from $4 \mu \mathrm{g} / \mathrm{mL}$ to $0.25 \mathrm{ng} / \mathrm{mL}$ ), and then the dilution series were transferred from 96-well clear round bottom microplates to 384 -well white optiplates $(2.5 \mu \mathrm{L} /$ well $)$ in triplicate using the Janus automated workstation. After cell dispensing, the following steps were performed sequentially as previously mentioned. All incubations were conducted at RT. U-50488 was included as positive control, and $0 \%$ and $100 \%$ controls were prepared to calculate the $Z^{\prime}$ factor value. The $\mathrm{EC}_{50}$ values of the tested compounds and U-50488 were calculated using comparisons with the corresponding cAMP standard curve in the same plate. SAR studies were further conducted after obtaining secondary screening results.

\section{Identification of in vivo analgesic function}

The animals were transported to the behavioral testing room one day prior to testing. The mice were acclimated in the 
observation cage at least $1 \mathrm{~h}$ before the experiments.

The animals were divided into seventeen groups of ten animals each as follows: the normal control group, the positive control group (40 $\mu \mathrm{g} / \mathrm{kg} \mathrm{U}-50488)$, and three dosing groups for each compound (I-7, I-8, I-10, II-5, and II-8; each compound dosed at 10, 20, and $40 \mu \mathrm{g} / \mathrm{kg}$ ). The doses were selected based on the observations of our preliminary study (unpublished data).

The mice were injected intraperitoneally (ip) with normal saline, U-50488, or compound I-7, I-8, I-10, II-5, and II-8. After $30 \mathrm{~min}$, each animal was injected ip with a $0.7 \%(v / v)$ acetic acid solution $(10 \mathrm{~mL} / \mathrm{kg}$ of body weight) as an irritant stimulus and placed in an individual plastic cage for observation. After a 5-min period, the number of writhes was recorded for $20 \mathrm{~min}$, and latency was also recorded. A writhe was defined as stretching of the hind limbs accompanied by a contraction of the abdominal muscles. For the writhing test, the number of abdominal constrictions in each test period was normalized to the mean calculated from the control group as percent inhibition of writhing (\% inhibition) based on the formula in $\mathrm{Eq}$ (2): $\%$ inhibition $=(\mathrm{C}-\mathrm{T}) / \mathrm{C} \times 100 \%$, where $\mathrm{C}$ is the mean number of writhes in the control animals and $\mathrm{T}$ is the number of writhes in the drug-treated mice.

\section{Antagonist studies}

To assess the possible involvement of the KOR system in the analgesia effects of compounds in the acetic acid stretching experiment, an additional series of experiments were conducted. The positive group and the high dose groups of compounds I-10 and II- 8 were pretreated with the selective K-opioid receptor antagonist nor-binaltorphimine (nor-BNI, $200 \mu \mathrm{g} / \mathrm{kg}$, ip). Fifteen hours after nor-BNI administration, the mice were administered U-50488 or compounds I-10 or II-8 (40 $\mu \mathrm{g} / \mathrm{kg}, \mathrm{ip})$. After $30 \mathrm{~min}$, each animal was injected ip with a $0.7 \%(v / v)$ acetic acid solution $(10 \mathrm{~mL} / \mathrm{kg}$ of body weight $)$ and subjected to the acetic acid-induced writhing test.

\section{Statistical analysis}

All data are displayed as the mean \pm SEM, unless otherwise specified. The screening model and secondary screening experiments were performed in triplicate and repeated thrice. Preliminary screening was performed in a single well. Data were analyzed with GraphPad Prism 5.0 (GraphPad Software, San Diego, CA, USA). Nonlinear regression analyses were performed to generate dose-response curves and calculate $\mathrm{EC}_{50}$ values. For the pharmacodynamic studies, statistical analyses were performed using one-way ANOVA followed by Tukey's multiple comparison test to determine the source of significant differences where appropriate; $P<0.01$ were considered statistically significant. GraphPad Prism 5.0 software was used for statistics and plotting.

\section{Results}

\section{Optimization of the LANCE ${ }^{\mathrm{TM}}$ cAMP assay}

To achieve the most reproducible and sensitive assay, several parameters were defined. The influence of various cell densi- ties on forskolin dose-response curves is presented in Figure 1. The standard curves were performed in parallel, and the forskolin dose-response curve using 600 cells $/ \mu \mathrm{L}$ covered the most linear region of the corresponding cAMP standard curve at various stimulation times. Thus, 600 cells $/ \mu \mathrm{L}$ was selected as the optimal cell density. With regard to the influence of incubation time in the 600 cells $/ \mu \mathrm{L}$ forskolin dose-response curve, the 45-min stimulation time revealed the highest S/B ratio (Figure 2). Similarly, the optimal forskolin concentration was calculated using the 600 cells $/ \mu \mathrm{L}$ forskolin dose-response curve at 45-min stimulation time, and this value equaled 11.5 $\mu \mathrm{mol} / \mathrm{L}$, which induced $90 \%$ of its maximal effect $\left(\mathrm{EC}_{90}\right)$ (Figure 1C). Therefore, the following optimized parameters were used in subsequent assays: 600 cells $/ \mu \mathrm{L}$ cell density, $45-\mathrm{min}$ stimulation time, and $11.5 \mu \mathrm{mol} / \mathrm{L}$ forskolin concentration.

\section{Verification of the positive drug assay}

The agonist U-50488 decreased forskolin-stimulated cAMP accumulation in a concentration-dependent manner. The $\mathrm{EC}_{50}$ of U-50488 calculated from Figure 3 was $1.572 \pm 0.41 \mathrm{nmol} / \mathrm{L}$. This result is similar to the data previously reported by Berg et al, 2011 ${ }^{[17]}$. The average $Z^{\prime}$ factor value from three experiments was 0.79 (data not shown), which indicates an optimal assay because the value was greater than 0.5 . Therefore, the above data indicate that our system is a stable and reliable cell-based, high-throughput screening system for identifying potential KOR agonists.

\section{Preliminary screening}

Preliminary screening was accomplished in 228 384-well white optiplates. We screened 80000 compounds at a concentration of $10 \mu \mathrm{g} / \mathrm{mL}$ using this optimized system. The average $Z^{\prime}$ factor and S/B values for this screen were 0.65 and 4.06 , respectively (Figure 4A), indicating that the assay was adequately adapted for HTS. Upon preliminary screening, 137 compounds demonstrating stimulation percentages greater than $80 \%$ were selected and further validated by secondary screening $(1.7 \%$ hit rate).

\section{Secondary screening}

In total, 137 compounds were screened in 35 384-well white optiplates. The average $Z^{\prime}$ value was 0.64 , whereas the S/B ratio was 4.23 (Figure $4 \mathrm{~B}$ ). The average $\mathrm{EC}_{50}$ value for $\mathrm{U}-50488$ was $1.61 \pm 0.64 \mathrm{nmol} / \mathrm{L}$ (Figure $5 \mathrm{~A}$ ), consistent with previous observations. The $\mathrm{EC}_{50}$ values of 137 compounds were determined from eight-point dose-response curves. In total, 31 compounds displayed obvious dose-response activities (0.39\% hit rate) (Table 1$)$. Among these compounds, five compounds displayed significant stimulating activity compared with U-50488; these dose-response curves are presented in Figure 5B. The $\mathrm{EC}_{50}$ values of I-7, I-8, I-10, II-5, and II- 8 were $13.34 \pm 1.65,14.01 \pm 1.84,9.57 \pm 0.19,14.94 \pm 0.64$, and $8.74 \pm 0.72$ nmol/L, respectively. Furthermore, the 31 compounds could be divided into three groups based on their structures (Figure 6). SAR studies demonstrated that the compounds with an amide group in the R1 group and a halogen atom in the 
A

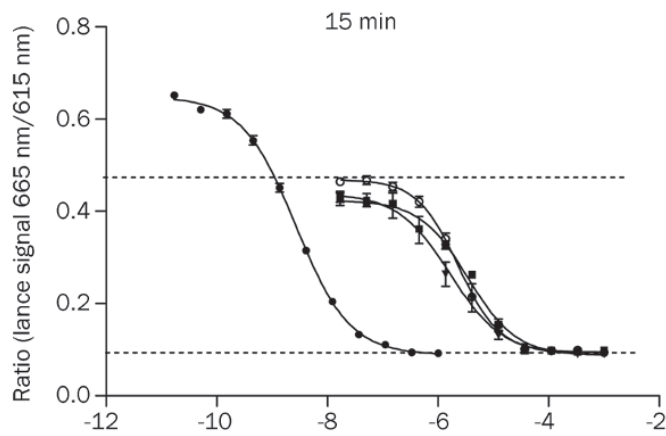

C

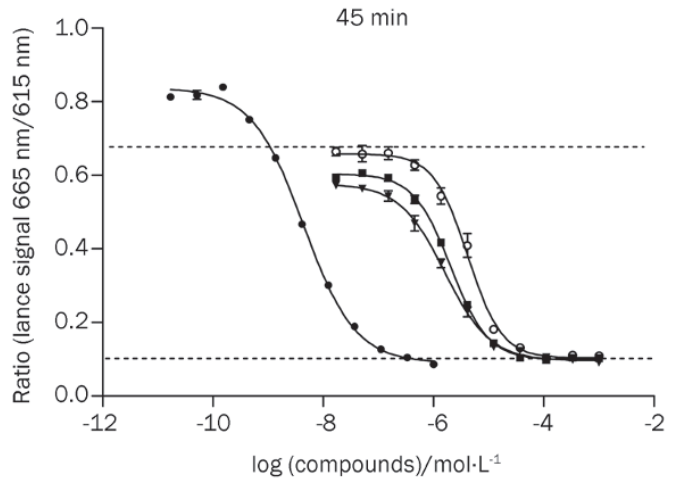

B

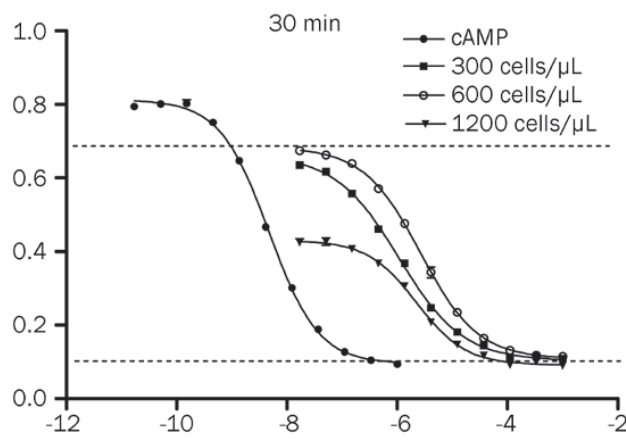

D

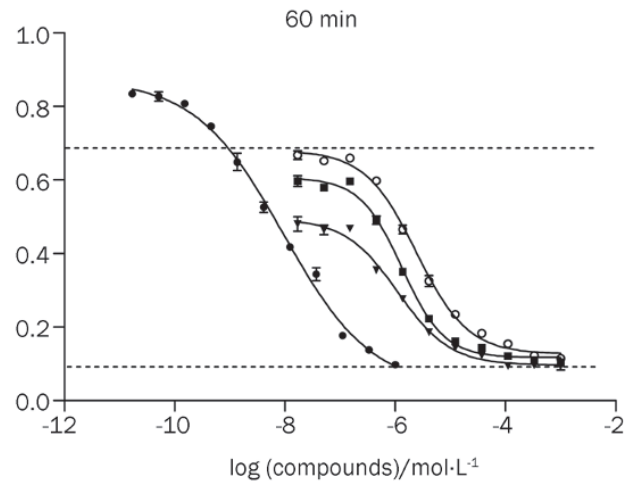

Figure 1. Forskolin dose-response curves using various cell densities stimulation times. The optimal cell density was set as 600 cells/ $\mu \mathrm{L}$ given that its curve covers the majority of the linear region of the cAMP standard curve at 15 (A), 30 (B), 45 (C), and 60 (D) min of stimulation. The values were bestfit using nonlinear regression. The points represent the mean \pm SEM of three independent experiments performed in triplicate. The compounds in the $\mathrm{X}$-axis title represent forskolin and cAMP.

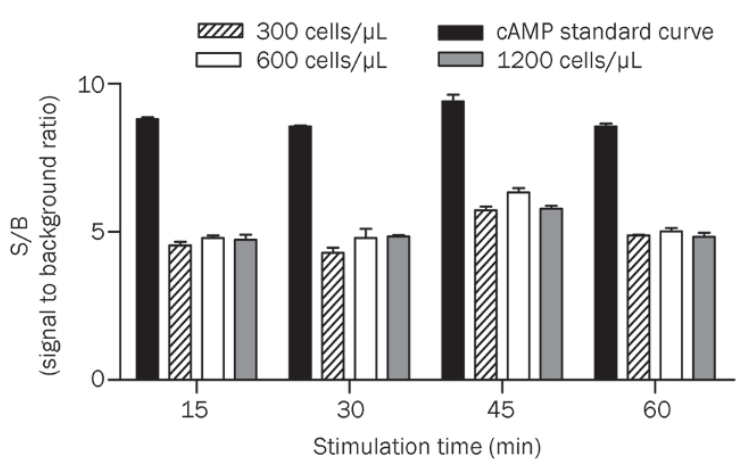

Figure 2. S/B ratios of cAMP standard curves and forskolin dose-response curves using various cell densities and stimulation times. In the 600 cells/ $\mu \mathrm{L}$ forskolin dose-response curve, a 45 min forskolin stimulation time exhibited the highest S/B ratio. These ratios were generated by twoway ANOVA. The values represent the mean \pm SEM of three independent experiments performed in triplicate.

R3 group display better stimulating activities in group I. In group II, the compounds with a small phenylamine group in the R group and an alkyl group are more potent stimulators. In group III, the compounds with a small ester group in the $\mathrm{R} 1$ group with a bromine atom in the R3 group are superior stimulators.

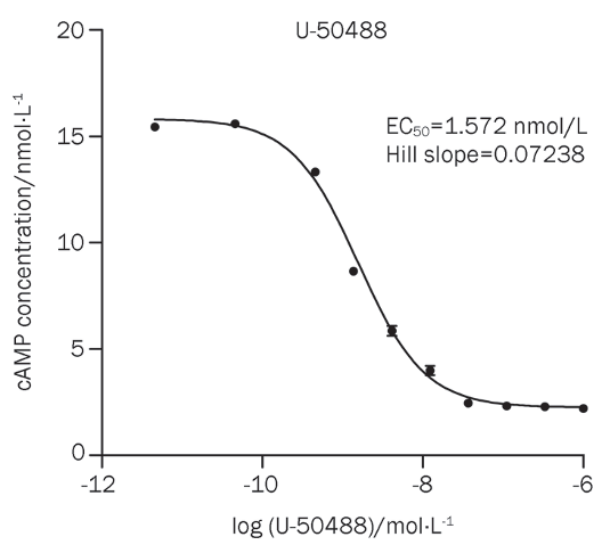

Figure 3. U-50488 dose-response curve generated under the optimal assay conditions. The total amount of cAMP accumulation was determined by interpolation of the signals obtained with various U-50488 doses on a cAMP standard curve. The values were best-fit to a log (agonist) vs response stimulation. The $\mathrm{EC}_{50}$ of U-50488 was $1.572 \pm 0.41 \mathrm{nmol} / \mathrm{L}$. The points represent the mean \pm SEM of three independent experiments performed in triplicate.

\section{In vivo analgesic function identification}

In this study, compounds I-10 and II-8 displayed significant analgesic effects, whereas compounds I-7, I-8, and II-5 dis- 

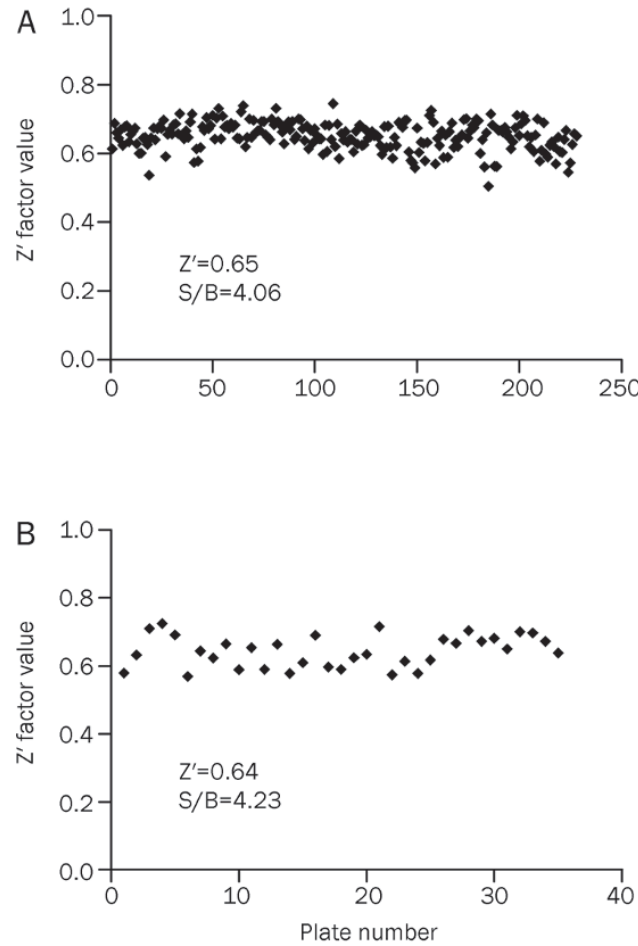

Figure 4. (A) $Z^{\prime}$ factor values of 228 plates from preliminary screening (B) $Z^{\prime}$ factor values of 35 plates from secondary screening.

Table 1. Kappa opioid receptor stimulating activity of 31 compounds. The values represent the mean \pm SEM of three independent experiments performed in triplicate.

\begin{tabular}{cccl}
\hline Compound & Group I & $\begin{array}{c}\mathrm{EC}_{50}(\mathrm{nmol} / \mathrm{L}) \\
\text { Group II }\end{array}$ & \multicolumn{1}{c}{ Group III } \\
\hline 1 & $75.18 \pm 2.67$ & $125.78 \pm 0.68$ & $92.79 \pm 1.05$ \\
2 & $93.35 \pm 1.71$ & $113.4 \pm 0.96$ & $115.2 \pm 2.8$ \\
3 & $93.87 \pm 2.32$ & $94.37 \pm 0.75$ & $93.54 \pm 1.15$ \\
4 & $65.34 \pm 3.72$ & $53.92 \pm 2.33$ & $76.79 \pm 2.7$ \\
5 & $36.49 \pm 2.43$ & $14.94 \pm 0.64$ & $74.35 \pm 2.26$ \\
6 & $35.79 \pm 1.37$ & $82.96 \pm 1.59$ & $56.99 \pm 1.29$ \\
7 & $13.34 \pm 1.65$ & $60.04 \pm 2.31$ & $63.21 \pm 1.27$ \\
8 & $14.01 \pm 1.84$ & $8.74 \pm 0.72$ & $77.13 \pm 2.44$ \\
9 & $55.15 \pm 1.65$ & $70.68 \pm 1.05$ & $75.39 \pm 1.58$ \\
10 & $9.57 \pm 0.19$ & $36.29 \pm 2.8$ & $53.86 \pm 1.13$ \\
11 & & & $65.68 \pm 1.24$
\end{tabular}

$\mathrm{EC}_{50}$ is expressed as the KOR stimulating activity, which was calculated in Prism using nonlinear regression fit.

played minimal effects. The antinociceptive effects induced by U-50488 and various doses of compounds I-10 and II-8 in the mouse writhing test are displayed in Table 2. The U-50488 group significantly reduced the writhing response compared with the control $(P<0.01)$. Compounds I-10 and II-8 $(20-40$ $\mu \mathrm{g} / \mathrm{kg}$, ip) also significantly reduced the number of writhes induced by acetic acid $[0.7 \%(v / v)]$ in mice $(P<0.01)$. The effect
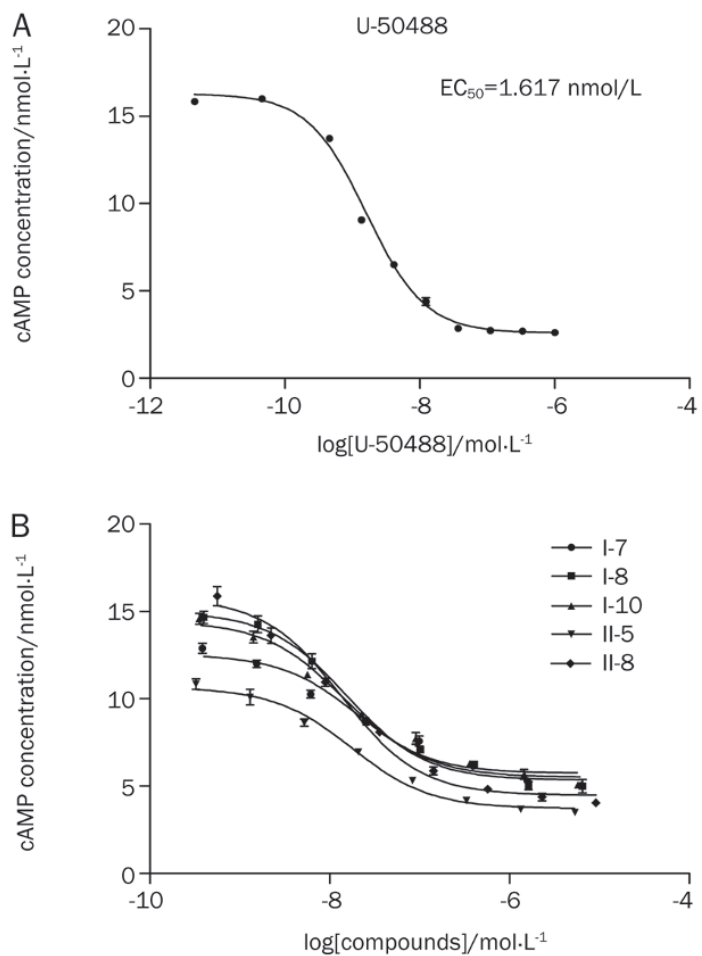

Figure 5. Dose-response curves of compounds that displayed potent KOR stimulation compared with U-50488. Total amount of cAMP accumulation was determined by interpolation of the signals obtained with various compound doses on a cAMP standard curve. Values were best-fit to a log (agonist) vs response stimulation. The points represent the mean \pm SEM of three independent experiments performed in triplicate.

Table 2. The effects of U-50488 and compounds I-10 and II-8 on acetic acid-induced abdominal writhing in the presence and absence of nor-BNI. Mean \pm SEM. $n=10$. The symbols report significance level. ${ }^{\mathrm{c}} P<0.01$ vs control group. ${ }^{f} P<0.01$ the $40 \mu \mathrm{g} / \mathrm{kg}$ drug dose group in the presence vs absence of nor-BNI.

\begin{tabular}{|c|c|c|c|}
\hline $\begin{array}{l}\text { Drug \& doses } \\
\qquad(\mu g / k g)\end{array}$ & $\begin{array}{l}\text { Number of } \\
\text { writhings }\end{array}$ & $\begin{array}{l}\text { Latency } \\
\text { (min) }\end{array}$ & $\begin{array}{c}\text { Percent } \\
\text { inhibition } \\
(\%)\end{array}$ \\
\hline Control & $39.4 \pm 2.8$ & $4.8 \pm 1.6$ & \\
\hline U-50488 (40) & $8.8 \pm 1.0^{c}$ & $11.2 \pm 1.4$ & 77.7 \\
\hline U-50488 (40)+nor-BNI (200) & $34.1 \pm 3.3^{f}$ & $4.7 \pm 1.1$ & 13.5 \\
\hline Compound I-10 (10) & $44.2 \pm 3.1$ & $5.7 \pm 1.1$ & 0 \\
\hline Compound I-10 (20) & $25.0 \pm 2.6^{c}$ & $9.1 \pm 2.4$ & 36.5 \\
\hline Compound I-10 (40) & $19.8 \pm 3.0^{c}$ & $10.8 \pm 2.2$ & 49.7 \\
\hline Compound I-10 (40)+nor-BNI (200) & $39.2 \pm 2.4^{f}$ & $4.2 \pm 1.5$ & 0.5 \\
\hline Compound II -8 (10) & $35.4 \pm 4.2$ & $6.3 \pm 2.3$ & 10.2 \\
\hline Compound II-8 (20) & $26.2 \pm 5.0^{c}$ & $7.2 \pm 1.5$ & 33.5 \\
\hline Compound II-8 (40) & $14.8 \pm 1.9^{c}$ & $13.5 \pm 2.8$ & 62.4 \\
\hline Compound II-8 (40)+nor-BNI (200) & $30.3 \pm 3.6^{f}$ & $4.5 \pm 1.2$ & 23.1 \\
\hline
\end{tabular}

$\mathrm{EC}_{50}$ is expressed as the KOR stimulating activity, which was calculated in Prism using nonlinear regression fit. 
www.chinaphar.com

Wang $Y$ et al

npg

963
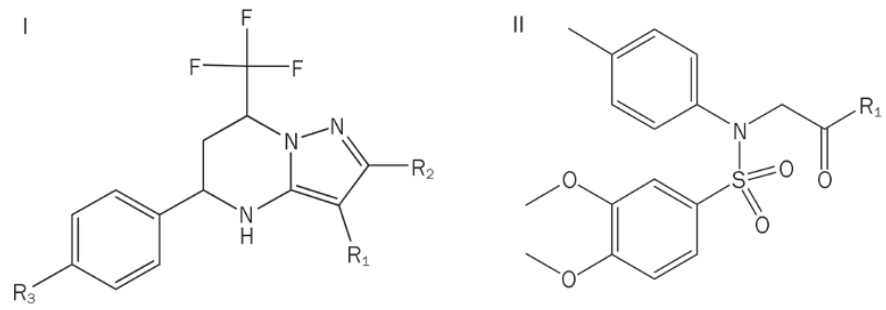

III<smiles>[R]OC(=O)c1c(C)oc2cc([R])c(O[R])cc12</smiles>

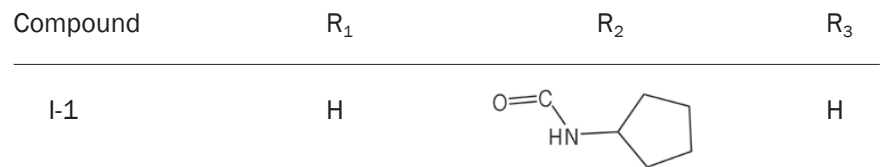

I-2

Cl

I-3

Cl

1-4

$\mathrm{H}$

$1-5$

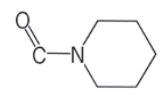

I-6

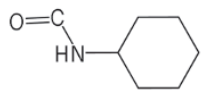

I-7

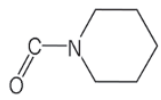

$1-8$

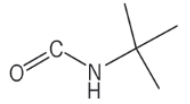

$1-9$

$\mathrm{H}$

I-10

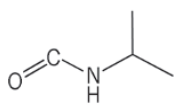

II-1

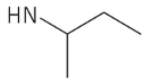

II-2

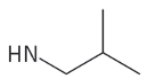

II-3

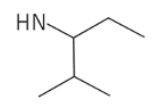

II-4

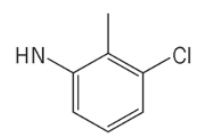

II-5

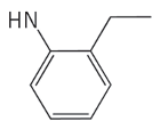

II-6
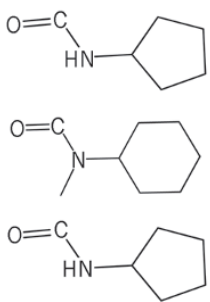

$\mathrm{H}$

$\mathrm{H}$

$\mathrm{H}$

III-2

$\mathrm{H}$

F

III-3

$\mathrm{H}$

F

$\mathrm{Br}$<smiles>CC(C)NC=O</smiles>

$\mathrm{H}$

$\mathrm{Br}$

III-6

III-7

|II-4

III-5

III-8

III-9

III-10

III-11

II-7

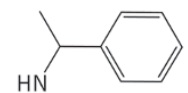

$\mathrm{R}_{1}$
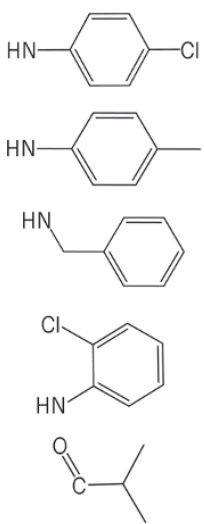

$\mathrm{CH}_{2} \mathrm{CH}_{3}$

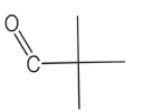

$\mathrm{CH}_{2} \mathrm{CH}_{3}$

$\mathrm{CH} 3$

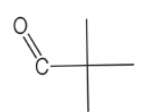

H

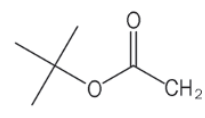

$\mathrm{CH}\left(\mathrm{CH}_{3}\right)_{2}$

H

$\mathrm{Br}$

$r_{0}$

$\mathrm{CH}_{3}$

$\mathrm{CH}_{2} \mathrm{CH}_{3}$

$\mathrm{Br}$

$\sim_{\mathrm{CH}_{2}}^{\mathrm{O}}$

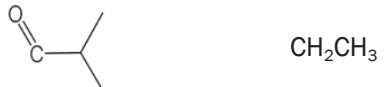

$\mathrm{Br}$

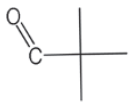

$\mathrm{CH}_{3}$

$\mathrm{Br}$

Ol $\quad \mathrm{CH}_{2} \mathrm{CH}_{3}$

$\mathrm{CH}_{2} \mathrm{CH}_{3}$

$\mathrm{Br}$

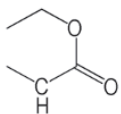

$\mathrm{CH}\left(\mathrm{CH}_{3}\right)_{2}$

$\mathrm{Br}$

Figure 6. Structures of selected compounds. I: 5-phenyl-7-(trifluoromethyl)-4,5,6,7-tetrahydropyrazolo[1,5-a]pyrimidine; II: 3,4-dimethoxy- $N$-(2-oxoethyl)$\mathrm{N}$-p-tolylbenzenesulfonamide: III: 5-hydroxy-2-methylbenzofuran-3-carboxylic acid.

Acta Pharmacologica Sinica 
of compound I-10 was weaker than II-8; the maximum percent suppression produced by compounds I-10 (40 $\mu \mathrm{g} / \mathrm{kg}$, ip) and II-8 (40 $\mu \mathrm{g} / \mathrm{kg}$, ip) was $49.7 \%$ and $62.4 \%$, respectively.

\section{Antagonist studies}

Compounds I-7, I-8, and II-5 displayed minimal effects; therefore, we only conducted the antagonist studies with compounds I-10 and II- 8 . The analgesic effects of the coadministration of the KOR agonist standard U-50488 or compounds I-10 and II- 8 with nor-BNI on the writhing test in mice are presented in Table 2. U-50488 and compounds I-10 and II-8 $(40 \mu \mathrm{g} / \mathrm{kg}$, ip) significantly reduced the number of writhes $(P<0.01)$ when administered individually. The co-administration of the selective KOR antagonist nor-BNI $(200 \mu \mathrm{g} / \mathrm{kg}$, ip) notably antagonized the analgesic effects of U-50488 and compounds I- 10 and II- 8 and increased the number of writhes approximately four- and two-fold, respectively, with a comparable reduction in percent inhibition.

\section{Discussion}

It has been well documented that KOR agonists, such as Salvinorin A, U-69593, and U-50488, mediate the majority of the pharmacological effects linked to opioid receptor activation, such as cardiac hypertrophy, myocardial fibrosis, arrhythmia, mood disorders and neuralgia ${ }^{[6,18-20]}$. Among these agents, U-50488 has been used as a highly selective kappa opioid agonist given that it displays a 30 - to 54 -fold increased affinity for the kappa subtype than the mu and delta subtypes ${ }^{[10,21,22]}$. U-50488 produces less morphine-type physical dependence than other reputed KOR agonists ${ }^{[22]}$. Therefore, we test the effects of 80000 compounds to discover potential KOR agonists and used U-50488 as the positive control in this assay.

A sensitive and robust assay is critical to ensure a successful HTS study. A search for KOR stimulants also requires an assay that maximizes the chance of identifying possible agonists. In this study, we performed a LANCE ${ }^{\mathrm{TM}}$ CAMP assay to monitor intracellular cAMP levels. To measure the assay sensitivity, we performed optimization experiments (Figure 1) that examined the signal produced from various reagent concentrations and cell densities. The $Z^{\prime}$ factor calculated from the positive drug verification experiment was greater than 0.7 (data not shown). These results clearly demonstrate that a condition could be selected from the screening model experiment to ensure assay sensitivity and robustness. Owing to its high sensitivity, the assay is widely used in HTS, which is based on TR-FRET approach ${ }^{[23]}$. The entire procedure occurs in a single well of a 384-well microplate with no transfer, separation, or wash steps; this feature guarantees experiment reliability. The assay performance is ideal for adaptation to the HTS environment in terms of the speed of analysis, precision, and detection limits for cAMP quantification. These attributes suggest that this assay can accurately assess potential KOR agonists $^{[24]}$.

An HTS campaign of 80000 compounds was performed under the optimal conditions. In preliminary screening, 137 compounds with stimulation percentage values greater than
$80 \%$ were identified for further screening. However, the results indicate that only 31 compounds display dose-response activities. The high false positive ratio $(77.4 \%)$ was initially attributed to cell number inconsistency in each well caused by the Multidrop dispenser. Later in the preliminary screening, we discovered that a large amount of cells were adhered to the instrument tubing. However, the average $Z^{\prime}$ factor value obtained from preliminary screening assuaged this concern and demonstrated the reliability of the compounds' stimulation percentage values.

Overall, 31 compounds displayed obvious dose-response activity in secondary screens. The compounds were divided into three groups based on structure (group I, group II, and group III). Each group had different parent structures, whereas compounds in the same group shared a common parent structure (Figure 6). The $\mathrm{EC}_{50}$ values of compounds from the same group were different, and some values were similar to the $\mathrm{EC}_{50}$ value of U-50488. Thus, structurally distinct compounds can stimulate KOR with varying potencies.

In group I, the compounds with an amide group in the R1 group and a halogen atom in the R3 group displayed increased KOR stimulating activity (Figure 6I). This increased activity may be attributed to the existence of an amide group in the R1 group, which forces the compounds to alter their spatial structures. This alteration contributes to the binding of compounds to the KOR binding sites. In addition, the amide group could form strong hydrogen bonds, which may promote priority binding with $\mathrm{KOR}^{[25]}$. The amide group in the $\mathrm{R} 1$ group is an essential pharmacophore that allows compounds to exert their efficacy. The $\mathrm{EC}_{50}$ values of compounds I-5 and I-7 are $36.49 \pm 2.43$ and $13.34 \pm 1.65 \mathrm{nmol} / \mathrm{L}$, respectively. The substituent in the R3 group is different for these compounds. Compound I-7 has a fluorine atom in the $\mathrm{R} 3$ group and displays increased potency. This structure-activity relationship is reflected in the $\mathrm{EC}_{50}$ values for compound I-6 $\left(\mathrm{EC}_{50}=35.79 \pm 1.37\right.$ $\mathrm{nmol} / \mathrm{L})$, compound I-8 $\left(\mathrm{EC}_{50}=14.01 \pm 1.84 \mathrm{nmol} / \mathrm{L}\right)$ and compound $\mathrm{I}-10\left(\mathrm{EC}_{50}=9.57 \pm 0.19 \mathrm{nmol} / \mathrm{L}\right)$. This phenomenon is potentially explained by the existence of a halogen atom that reduces the electron density on the benzene ring given its electron-withdrawing property and further promotes the interaction between the compounds and the receptor amino acid residues, thereby increasing the KOR stimulation action ${ }^{[26]}$. SAR studies indicate that the small size of the amide group in the $\mathrm{R} 1$ group and a halogen atom in the R3 group are essential for KOR stimulation in this group.

In group II, the compounds with a phenylamine in the $\mathrm{R}$ group exhibited increased activity compared with the aliphatic amine at KOR (Figure 6II). This activity may be attributed to the conjugate structure of the benzene ring and the amide bond, whether in space or electron density, which facilitates formation of intermolecular interactions with the receptor binding sites. Thus, the affinity of the compounds and receptor is enhanced ${ }^{[27]}$. This structure-activity relationship is also reflected in the $\mathrm{EC}_{50}$ values of compound II- $6\left(\mathrm{EC}_{50}=82.96 \pm 1.59\right.$ $\mathrm{nmol} / \mathrm{L})$ and II-9 $\left(\mathrm{EC}_{50}=70.68 \pm 1.05 \mathrm{nmol} / \mathrm{L}\right)$. The $\mathrm{EC}_{50}$ values of compound II- 5 and II- 8 are $14.94 \pm 0.64 \mathrm{nmol} / \mathrm{L}$ and $8.74 \pm 0.72$ 
nmol/L, respectively. The substitution of an alkyl on the benzene ring may contribute to the enhanced stimulation ability. Alkyl residues, which are considered electron-donating groups, improve receptor and molecule binding by increasing the electron density of the benzene ring ${ }^{[28]}$. Contrary to alkyl groups, chlorine atoms, which serve as electron-withdrawing groups, display the opposite effect ${ }^{[26]}$. Based on the SAR studies, the phenylamine with an alkyl group in the $\mathrm{R}$ group of group II compounds plays a definitive role in KOR stimulation. Based on this premise, the compounds display enhanced stimulation.

In group III, the compounds with an ester in the R1 group and a bromine atom in the R3 group display enhanced KOR stimulation compared with those compounds with a ketone in the R1 group (Figure 6III). This finding may result from the existence of a conjugate structure between the carbonyl and oxygen atom, which could reduce the electron density of the lone pair of oxygen electrons and further affect molecular and receptor binding ${ }^{[29]}$. The ester in the $\mathrm{R} 1$ group may be more beneficial to the compound's stimulating activity than the ketone group. SAR studies of two subgroups of compounds in group III (compound III-1 and III-7; compound III-3 and III8) reveal that analogs with a bromine atom in the R3 group exhibit relatively high activity. We hypothesize that the bromine atom promotes the interaction between the compounds and the receptor by reducing the electron density on the benzene ring ${ }^{[26]}$. According to the SAR studies, the ester and bromine atom in group III compounds play definitive roles in KOR stimulation.

The acetic acid-induced writhing test demonstrated that compound II-8 more potently inhibits acetic acid-induced writhing than compound I-10. The $\mathrm{EC}_{50}$ of compound II- 8 was reduced compared with compound I-10, which is consistent with the SAR studies. Furthermore, the analgesic effects of compounds I-10 and II- 8 were significantly antagonized in the presence of the selective KOR antagonist nor-BNI, which indicates that compounds I-10 and II- 8 are potential KOR agonists.

In summary, dose-response activity was observed with ten compounds from group I, ten in group II and eleven in group III. In group I, three compounds displayed $\mathrm{EC}_{50}$ values similar to U-50488, and two compounds from group II had similar values. The values were greater than those from group III. These findings indicate that the compounds with parent structures I or II may be considered with priority in drug design as potential KOR agonists rather than compounds with parent structure III.

In addition, although our study provided detailed data for the design and development of potent KOR agonists and identified five compounds with potent KOR stimulation, the KOR selectivity of these compounds remains unknown. Given the lack of CHO-OP1 and CHO-OP3 cell lines, the stimulating activity of the 31 compounds was not tested on MOR and DOR. The compounds we identified may be non-selective KOR agonist, similar to Dynorphin A or Dynorphin $\mathrm{B}^{[30,31]}$. We did not perform behavioral experiments in animals and mechanism of action studies for these compounds; therefore, we are unable to evaluate the degree of their addiction and dependence. In this aspect, further investigation of these compounds using more detailed selectivity studies is needed.

\section{Acknowledgements}

This project was supported by the National 12th Five-year Plan for "Major Scientific and Technological Special Project for Significant New Drugs Creation" project of "Novel G proteincoupled receptor targeted drug screening system and key technology research" (No 2012ZX09504001-001); the Program for New Century Excellent Talents in University (No NCET10-0817); the Major Scientific and Technological Special Project of Guangdong Province (№ 2012A080201005) and the Fundamental Research Funds for the Central Universities (No s JKZ2009005 and JKY2011052).

\section{Author contribution}

Ling HE designed research; Yue WANG and Ming YAN performed research and wrote the paper; Guang-yao ZHENG contributed new analytical tools and reagents; and Huan YANG analyzed data.

\section{References}

1 Kobilka BK. G protein coupled receptor structure and activation. Biochim Biophys Acta 2007; 1768: 794-807.

2 Long I, Andersson P, Seifert E, Lundstedt T. Multivariate analysis of five GPCR receptor classes. Chemometr Intell Lab Syst 2004; 73: 95-104.

3 van Rijn RM, Whistler JL, Waldhoer M. Opioid-receptor-heteromerspecific trafficking and pharmacology. Curr Opin Pharmacol 2010; 10: 73-9.

4 Tsai NP, Tsui YC, Pintar JE, Loh HH, Wei LN. Kappa opioid receptor contributes to EGF-stimulated neurite extension in development. Proc Natl Acad Sci U S A 2010; 107: 3216-21.

5 Kumar S, Rai U. Dynorphin regulates the phagocytic activity of splenic phagocytes in wall lizards: involvement of a kappa-opioid receptorcoupled adenylate-cyclase-cAMP-PKA pathway. J Exp Biol 2011; 214: 4217-22.

6 Romero TR, Guzzo LS, Duarte ID. Mu, delta, and kappa opioid receptor agonists induce peripheral antinociception by activation of endogenous noradrenergic system. J Neurosci Res 2012; 90: 165461.

7 Resendez SL, Kuhnmuench M, Krzywosinski T, Aragona BJ. kappaOpioid receptors within the nucleus accumbens shell mediate pair bond maintenance. J Neurosci 2012; 32: 6771-84.

8 Wang YJ, Rasakham K, Huang P, Chudnovskaya D, Cowan A, LiuChen LY. Sex difference in kappa-opioid receptor (KOPR)-mediated behaviors, brain region KOPR level and KOPR-mediated guanosine $5^{\prime}-0-\left(3-\left[{ }^{35}\right.\right.$ S $]$ thiotriphosphate)binding in the guinea pig. J Pharmacol Exp Ther 2011; 339: 438-50.

9 Lahti RA, Mickelson MM, McCall JM, Von Voigtlander PF. $\left[{ }^{3} \mathrm{H}\right]$ U-69593 a highly selective ligand for the opioid kappa receptor. Eur J Pharmacol 1985; 109: 281-4.

10 Lahti RA, VonVoigtlander PF, Barsuhn C. Properties of a selective kappa agonist, U-50488H. Life Sci 1982; 31: 2257-60.

11 Pan ZZ. mu-Opposing actions of the kappa-opioid receptor. Trends Pharmacol Sci 1998; 19: 94-8.

12 Aldrich JV, McLaughlin JP. Peptide kappa opioid receptor ligands: potential for drug development. AAPS J 2009; 11: 312-22. 
13 Arendt-Nielsen L, Olesen AE, Staahl C, Menzaghi F, Kell S, Wong GY, et al. Analgesic efficacy of peripheral kappa-opioid receptor agonist CR665 compared to oxycodone in a multi-modal, multi-tissue experimental human pain model: selective effect on visceral pain. Anesthesiology 2009; 111: 616-24.

14 Coop A, Rice KC. Role of delta-opioid receptors in biological processes. Drug News Perspect 2000; 13: 481-7.

15 Bridges D, Thompson SWN, Rice ASC. Mechanisms of neuropathic pain. Br J Anaesthesia 2001; 87: 12-26.

16 Zhang JH, Chung TD, Oldenburg KR. A simple statistical parameter for use in evaluation and validation of high throughput screening assays. J Biomol Screen 1999; 4: 67-73.

17 Berg KA, Rowan MP, Sanchez TA, Silva M, Patwardhan AM, Milam SB, et al. Regulation of kappa-opioid receptor signaling in peripheral sensory neurons in vitro and in vivo. J Pharmacol Exp Ther 2011; 338: 92-9.

18 Lutz PE, Kieffer BL. Opioid receptors: distinct roles in mood disorders. Trends Neurosci 2013; 36: 195-206.

19 Yin W, Zhang P, Huang JH, Zhang QY, Fan R, Li J, et al. Stimulation of kappa-opioid receptor reduces isoprenaline-induced cardiac hypertrophy and fibrosis. Eur J Pharmacol 2009; 607: 135-42.

20 Jin-Cheng L, Wen Y, Zhao Y, Quan-Yu Z, Shu-Miao Z, Hai-Tao G, et al. Anti-arrhythmic effects of kappa-opioid receptor and its changes in ischemia and reperfusion. Arch Med Res 2008; 39: 483-8.

21 Clark JA, Pasternak GW. U50488: a kappa-selective agent with poor affinity for mu1 opiate binding sites. Neuropharmacology 1988; 27 : 331-2.

22 Von Voigtlander PF, Lewis RA. U-50488, a selective kappa opioid agonist: comparison to other reputed kappa agonists. Prog Neuropsychopharmacol Biol Psychiatry 1982; 6: 467-70.
23 Maurel D, Kniazeff J, Mathis G, Trinquet E, Pin JP, Ansanay H. Cell surface detection of membrane protein interaction with homogeneous time-resolved fluorescence resonance energy transfer technology. Anal Biochem 2004; 329: 253-62.

24 Prystay L, Gagne A, Kasila P, Yeh LA, Banks P. Homogeneous cellbased fluorescence polarization assay for the direct detection of cAMP. J Biomol Screen 2001; 6: 75-82.

25 Cong $\mathrm{Y}$, Klaus $\mathrm{M}$. Molecular imprinting utilizing an amide functional group for hydrogen bonding leading to highly efficient polymers. J Org Chem 1997; 62: 4057-64.

26 Clark T, Hennemann M, Murray JS, Politzer P. Halogen bonding: the sigma-hole. Proceedings of "Modeling interactions in biomolecules II", Prague, September 5th-9th, 2005. J Mol Model 2007; 13: 2916.

27 Yamashita Y. Organic semiconductors for organic field-effect transistors. Sci Tech Adv Materials 2009; 10: 024313.

$28 \mathrm{Cho} \mathrm{CH}$, Kang $\mathrm{H}$, Kang TE, Cho HH, Yoon SC, Jeon MK, et al. Controlling side-chain density of electron donating polymers for improving their packing structure and photovoltaic performance. Chem Commun (Camb) 2011; 47: 3577-9.

29 O'Hagan D. Understanding organofluorine chemistry. An introduction to the C - F bond. Chem Soc Rev 2008; 37: 308-19.

30 Chavkin C, Henriksen SJ, Siggins GR, Bloom FE. Selective inactivation of opioid receptors in rat hippocampus demonstrates that dynorphin$A$ and $-B$ may act on mu-receptors in the CA1 region. Brain Res 1985; 331: 366-70.

31 Guerrini R, Capasso A, Marastoni M, Bryant SD, Cooper PS, Lazarus $\mathrm{LH}$, et al. Rational design of dynorphin A analogues with delta-receptor selectivity and antagonism for delta- and kappa-receptors. Bioorg Med Chem 1998; 6: 57-62. 